\title{
El derecho a la ciudad. Praxis de la utopía*
}

\section{Ana Sugranyes**}

\section{Resumen}

El derecho a la ciudad fue formulado en defensa de los chabolistas en Francia a finales de los años 60. A partir de los años 90, organizaciones civiles y foros internacionales en América Latina han retomado los valores de este derecho colectivo emergente para construir una propuesta de cambio y alternativa a las condiciones de vida urbana generadas por las políticas neoliberales. El derecho a la ciudad propicia el ejercicio pleno de la ciudadanía y de todos los derechos humanos, la producción y gestión social del hábitat, la gestión democrática de la ciudad, a través de la participación de la sociedad de forma directa; propugna la función social de la propiedad y de la ciudad, donde predomine el bien común sobre el derecho individual de propiedad, lo que implica el uso socialmente justo y ambientalmente sustentable del espacio urbano. Ahora este derecho está incorporado en la Constitución de Ecuador, el Estatuto de la Ciudad en Brasil y la Carta por el Derecho a la Ciudad en el Distrito Federal de México. Es una bandera política del "buen vivir" en ciudades de todo el mundo.

\section{Palabras clave}

Derechos colectivos; Derechos humanos; Participación ciudadana; Función Social de la Ciudad; Función Social de la propiedad; Desarrollo sustentable.

\section{Abstract: The Right to the City. Praxis of utopia}

The Right to the City was formulated in defence of the slum dwellers' claims in France at the end of the 1960s. Since the 1990s, many Latin American civil organizations and international forums have resumed the struggle for these emerging collective rights in order to construct a proposal for change and an alternative to the current urban conditions created by neoliberal policies. The Right to the City is based on the full recognition of citizenship and of human rights, the social production and management of habitat, the democratic management of the city by means of the direct participation of civil organizations. It advocates the social function of ownership of the city, where public wealth prevails over individual property rights, which implies the urban space is to be used with social justice in a sustainable environment. Nowadays this right is included in the new Constitution of Ecuador, the City Statute in Brazil, and the Charter for the Right to the City in Mexico Federal District. It is one of the "well being" political banners in many cities all over the world.

\section{Key words}

Collective Rights; Human Rights; Citizen Participation; Social Function of the City; Social Function of Ownership; Sustainable Development.

\footnotetext{
Recibido: 13/09/2010; aceptado: 4/11/2010

* Artículo basado en documentos de Ana Sugranyes y Charlotte Mathivet (vid. Sugranyes y Mathivet, 2010).

** Datos de contacto: Ana Sugranyes, PhD General Secretary, Habitat International Coalition (HIC). Bueras 142, Of. 22. 8320135 Santiago, Chile. E-mail: asugranyes@gmail.com.
} 
En América Latina, en los Estados Unidos y, de forma dispersa en otras partes del mundo, el derecho a la ciudad es ahora una propuesta política de cambio y alternativa a las condiciones de vida urbana creadas por las políticas neoliberales. Según Purcell (2009), "el derecho a la ciudad de Lefebvre implica reinventar radicalmente las relaciones sociales del capitalismo y la estructura espacial de la ciudad". ${ }^{1}$ Es así como Lefebvre (1968, 3ª ed. 2009, p. 108) afirmaba que "el derecho a la ciudad no puede concebirse como el simple derecho de visita 0 de regreso a las ciudades tradicionales. Puede formularse solamente como derecho a la vida urbana, transformada, renovada".2

Esta reformulación de la vida urbana propone mayor equidad, donde la mayoría de los habitantes logren ser felices y solidarios, generando y redistribuyendo los beneficios de la ciudad para todas $y$ todos. Somos conscientes de los desafíos de esta aspiración de justicia social; algunos la llaman quimera o ilusión. Nosotros la llamamos utopía indispensable para otro mundo posible.

En esta gran tarea de (re)inventar condiciones del "buen vivir", o "Sumak Kawsay" ${ }^{3}$-como lo reclaman los indígenas andinos- es imprescindible construir estrategias globales para crear otra ciudad y otras relaciones humanas. Los movimientos sociales, como dijo Harvey (2009), juegan en eso un importante papel a través de sus luchas cotidianas por una sociedad más igualitaria, y específicamente por una ciudad más justa.

\section{Génesis y evolución de este derecho colectivo}

Recordemos el contexto histórico de la aparición

\footnotetext{
${ }^{1}$ Cita original en francés: «Le droit à la ville de Lefebvre implique de réinventer radicalement les relations sociales du capitalisme et la structure spatiale de la ville».

${ }^{2}$ Cita original en francés: «Le droit à la ville ne peut se concevoir comme un simple droit de visite ou de retour vers les villes traditionnelles. Il ne peut se formuler que comme droit à la vie urbaine, transformée, renouvelée».

3 "Sumak Kawsay es quichua ecuatoriano y expresa la idea de una vida no mejor, ni mejor que la de otros, ni en continuo desvivir por mejorarla, sino simplemente buena" (Tortosa, 2009).
}

del derecho a la ciudad, concepto, idea, programa (y no solo eslogan) definido en el libro Le droit à la ville, ${ }^{4}$ del filósofo y sociólogo francés Henri Le-febvre en 1968. Es la relación entre la pobreza urbana, la formulación intelectual crítica contra el sistema y el movimiento social de 1968 lo que retroalimenta el derecho a la ciudad formulado por Lefebvre.

Mirando a los diversos actores, y dentro de ellos a los movimientos sociales que reivindican el derecho a la ciudad en sus luchas, creemos que este derecho sigue teniendo una importancia en la vigencia del pensamiento de Lefebvre y de los que han continuado con el tema después de él. Esta vigencia y persistencia en el tiempo aparecen como su gran fuerza. Si bien en 1968 ha sido Lefebvre $^{5}$ con sus escritos y debates en las aulas sobre el derecho a la ciudad quien alimentó el movimiento estudiantil hacia la subversión y la rebeldía contra el orden establecido, hoy son los movimientos sociales con la bandera del derecho a la ciudad quienes se empoderan en sus luchas contra los efectos del sistema neoliberal, como la privatización de los espacios públicos, el uso mercantil de la ciudad, la predominancia de industrias y espacios mercantiles o la fragmentación del espacio urbano marcando nuevas barreras entre pobres y ricos.

Cuarenta y dos años después de la primera formulación del derecho a la ciudad es sorprendente que esta idea siga en pie y convoque a los movimientos sociales, académicos, organizaciones de la sociedad civil, tan heterogéneas, y en diferentes partes del mundo. Ni tan sorprendente, ya que las estrategias populares para luchar contra la lógica de la globalización mercantil actúan desde lo local con la perspectiva global del derecho a la ciudad. Además del debate académico sobre el sentido

\footnotetext{
${ }^{4}$ Vid. Lefebvre, 1968, Préface de R. Hess, S. Deulceux y G. Weigand.

${ }^{5} \mathrm{Y}$ los situacionistas, entre otros. Para este debate entre situacionistas y Lefebvre, vid. Simay, 2009.
} 
político del derecho a la ciudad y de los aportes legales para llegar a justicializar este derecho colectivo emergente, también es importante articular las luchas, describiéndolas en función de cada contexto local, con una mirada global para generar nexos, crear redes, y definir alianzas.

Según Jordi Borja (2000), "el desarrollo y legitimación de los derechos ciudadanos dependerá de un triple proceso: i) cultural, de hegemonía de los valores que están en la base de estos derechos y explicitación de los mismos; ii) social, de movilización ciudadana para conseguir su legalización y la creación de mecanismos y procedimientos que los hagan efectivos; iii) político-institucional para formalizarlos, consolidarlos y desarrollar las políticas para hacerlos efectivos".

El mismo autor afirma que los actores principales y emergentes de este proceso no son las estructuras políticas tradicionales de poder (estado y partidos políticos) sino grupos sociales, a veces muy heterogéneos.

Desde hace veinte años, la Coalición Internacional del Hábitat (HIC, de su sigla en inglés ${ }^{6}$ ) está involucrada en este triple proceso, acompañando a movimientos y grupos sociales de diferente índole. Hemos recogido muchas propuestas y experiencias que ilustran la diversidad de estos actores en la construcción del derecho a la ciudad, a través de conquistas, derrotas y rearticulaciones (en otras palabras: aciertos, errores y recomposiciones de fuerzas). Buscamos documentar estrategias políticas que emanan de esta diversidad de actores y que buscan incluir este enfoque de derecho colectivo en las instancias de toma de decisión. Es difícil mirar y entender los cambios, las rebeliones y las propuestas que surgen de los barrios y territorios. Cada una de estas expresiones corresponde a problemas distintos, de marginalidad, de delincuencia, de segregación, de autoconstrucción mal asistida, de estigmatización de la

\footnotetext{
${ }^{6}$ Para más información, ver el sitio <http://www.hic-net.org/>.
}

pobreza. Frente a estas realidades, tenemos que difundir nuevas miradas, que entiendan las singularidades locales, respeten la diversidad y rechacen los efectos perversos que conllevan las imágenes negativas creadas por el asistencialismo y el discurso mediático.

Como lo afirma el autor uruguayo Raúl Zibechi (2007, p. 8), "quienes estamos comprometidos con la causa de la emancipación y de los movimientos sociales, necesitamos promover reflexiones, análisis y formulaciones teóricas que reconozcan y aborden estas "sociedades otras", que las ciencias sociales del sistema tienen dificultad para visibilizar". Y agrega que es por esto que "estamos necesitados de pensamiento e ideas anclados en esas sociedades diferentes, no solo comprometidos con ellas sino formando parte de ellas" (ibíd.). Para entender las distintas facetas de estrategias y experiencias, cabe resaltar cuatro enfoques: las luchas populares contra la marginalización y los desalojos; las iniciativas populares de empoderamiento; la implementación del derecho a la ciudad a través del marco legal; la planificación y políticas públicas.

Estas estrategias están estrechamente articuladas entre ellas y tienen una lógica de continuidad en el tiempo desde la resistencia contra las violaciones del derecho a la ciudad a las acciones hacia su implementación. De esta manera, gracias a estas iniciativas populares de luchas sociales sostenidas durante décadas se ha logrado en varios países la incorporación del derecho a la ciudad en los marcos constitucionales y normativos como ya se ha logrado en Brasil, Ecuador, Bolivia y en la ciudad de México, pioneros en este gran desafío.

A menudo las políticas públicas y la planificación urbana se evidencian contrarias al derecho a la ciudad y al buen vivir, acelerando y profundizando los efectos negativos de la globalización mercantil. A su vez, pueden ser instrumentos que generan procesos de cambios, revirtiendo situaciones de 
desigualdad e injusticia.

La diversidad de actores involucrados para alcanzar cambios es el reflejo de esta misma voluntad que expresaba Zibechi de dar a conocer las ideas y las prácticas de los movimientos sociales, siempre y cuando mantengamos el respeto a estos movimientos, sin caer en el error de hablar en nombre de ellos. Otro desafío es el de acompañar a estos movimientos aportando las capacidades y los conocimientos respectivos. Conscientes de estos retos, se expresa la diversidad de caminos emancipatorios hacia la efectividad del derecho a la ciudad y la construcción de otra ciudad.

Es fundamental reconocer y sacar partido de esta diversidad de pensar el derecho a la ciudad y de actuar para implementarlo. Esto pasa por la articulación y retroalimentación entre los actores así como entre la teoría y la acción. El respeto de los procesos sociales, a través de una autocrítica permanente y una vigilancia de posibles usurpaciones del propósito inicial del derecho a la ciudad, puede evitar la tergiversación del discurso sobre este derecho.

Muchos cambios se han dado en el mundo entre la aparición del derecho a la ciudad en las aulas del profesor Lefebvre y las formas actuales de reivindicaciones de los movimientos sociales urbanos. El sociólogo estaba convencido de que el agente de cambio, la única clase social que podía lograr efectivamente una transformación de la sociedad y entonces de la ciudad, de implementar el derecho a la ciudad, era el proletariado encabezado por la clase obrera. Así afirmaba (ob. cit., p. 108) que "solo la clase obrera puede ser el agente, portador, o soporte social de esta realización". 7 En 2010, el escenario se ve diferente pues la clase obrera en el mundo globalizado neoliberal terciarizado se ha visto relegada a un segundo plano, sin el papel político que había tenido antes. Por eso,

\footnotetext{
${ }^{7}$ Cita original en francés: «Seule la clase ouvrière peut devenir l'agent, porteur, ou support social de cette réalisation».
}

movimientos sociales, organizaciones, intelectuales, militantes y activistas muy diversos, pero todos buscando el cambio social, se reivindican como colectivo movilizado del movimiento por el derecho a la ciudad y ya no como parte de la clase obrera. Uno de los cambios más relevantes que se han dado en estas últimas décadas es el reconocimiento del rol de la mujer dentro de estos procesos. Asimismo, es de suma importancia reconocer la discriminación adicional hacia la mujer en el espacio público a la hora de construir ciudades más equitativas.

También es importante destacar el rol que el espacio del Foro Social Mundial (FSM) ha facilitado para los movimientos sociales y para su articulación en expresiones globales en torno a diferentes derechos emergentes colectivos en el mundo, entre ellos la marcha mundial de las mujeres, la soberanía alimentaria, los pueblos indígenas, los afrodescendientes, los inmigrantes y ahora el derecho a la ciudad. Efectivamente, el FSM desde hace diez años ha facilitado estrategias globales para que diferentes movimientos se conozcan, intercambien, aprendan y reanalicen su propia experiencia a la luz de lo discernido en otros movimientos. Esto ha llevado a movimientos y redes a formular Cartas, Declaraciones y Agendas para seguir con la lucha por el derecho a la ciudad.

Los avances hacia el derecho a la ciudad enfrentan ahora un momento decisivo. La ONU, que no se caracteriza particularmente por su apoyo a las luchas sociales, internalizó el derecho a la ciudad, en la convocatoria del Foro Urbano Mundial 5 (FUM), en Río de Janeiro ${ }^{8}$. Ante este gran desafío, HIC colocó en esta feria urbana institucional y empresarial el rol de la sociedad civil que viene surgiendo desde hace décadas. Si la ONU ha incorporado el derecho a la ciudad en el FUM 5 es porque Brasil es el país en donde movimientos y or-

${ }^{8}$ World Urban Forum 5: The Right to the City-Bridging the Urban Divide. Rio de Janeiro, Brasil, 22 al 26 de marzo de 2010: $<$ http://www.unhabitat.org/categories.asp?catid=584>. 
ganizaciones sociales están construyendo este derecho desde hace más de veinte años. Sin embargo, esta oficialización del derecho a la ciudad también conlleva peligros de instrumentalización de estas luchas y del tema, que, por la diversidad de sus estrategias y de actores, puede resultar fácil de vaciar de su contenido de transformación de la ciudad y del sistema que la rige. En esta perspectiva, la preparación del Foro Social Urbano, organizado por primera vez en Río a la par del espacio institucional del FUM, ha marcado un hito importante en estos esfuerzos de construir un movimiento global por el derecho a la ciudad desde los movimientos sociales.

\section{Para entender $y$ apoderarse del derecho a la ciudad ${ }^{9}$}

El derecho a la ciudad no es una propuesta nueva. Como se ha dicho, el término se difundió con Henri Lefebvre analizando el impacto negativo sufrido por las ciudades en los países de economía capitalista, con la conversión de la ciudad en una mercancía al servicio exclusivo de los intereses de la acumulación del capital.

Como contrapropuesta a este fenómeno, Lefebvre construye una propuesta política que parte de la ciudad para reivindicar la posibilidad de que la gente volviera a ser dueña de la ciudad. Frente a los efectos causados por el neoliberalismo, se propone una nueva perspectiva política: la ciudad ha sido tomada por los intereses del capital y así ha dejado de pertenecer a la gente; a través del derecho a la ciudad, Lefebvre aboga por "rescatar el hombre como elemento principal, protagonista de la ciudad que él mismo ha construido". El derecho a la ciudad es entonces restaurar el sentido de ciudad, instaurar la posibilidad del "buen vivir" para todos y hacer de la ciudad "el escenario de encuentro para la construcción de la vida colectiva". Asimismo, la vida colectiva se puede construir so-

\footnotetext{
${ }^{9}$ Vid. en Mathivet, 2010, p. 23.
}

bre la base de la idea de la ciudad como producto cultural, colectivo y, en consecuencia, político. La ciudad, como lo analiza Jordi Borja (2003), es un espacio político, donde es posible la expresión de voluntades colectivas, es espacio para la solidaridad, pero también para el conflicto. El derecho a la ciudad es la posibilidad de construir una ciudad en la que se pueda vivir dignamente, reconocerse como parte de ella, y donde se posibilite la distribución equitativa de diferentes tipos de recursos: trabajo, salud, educación, vivienda y recursos simbólicos, como memoria, participación y acceso a la información.

El derecho a la ciudad es "el derecho de toda persona a crear ciudades que respondan a las necesidades humanas". Todo el mundo debería tener los mismos derechos para construir los diferentes tipos de ciudades que queremos. El derecho a la ciudad, como lo ha recalcado David Harvey (2009) -basándose en Lefebvre- durante el Foro Urbano Mundial en Belém, "no es simplemente el derecho a lo que ya está en la ciudad, sino el derecho a transformar la ciudad en algo radicalmente distinto".

La reivindicación de la posibilidad necesaria de crear otra ciudad se basa en los derechos humanos, y más precisamente en los Derechos Económicos, Sociales y Culturales (DESC). El fenómeno de la ciudad es analizado y pensado en función de la ciudadanía y del espacio público, con una visión integral e interdependiente de los derechos humanos, para lograr la meta de recuperar la ciudad para todos sus habitantes. Cabe aclarar que el derecho a la ciudad no es un derecho más: es el derecho a hacer cumplir los derechos ya formalmente suscritos por los Estados en tratados internacionales e instrumentalizados en el marco legal y normativo de los países. Por eso el derecho a la ciudad se basa en una dinámica de procesos y de conquistas, en las cuales los movimientos sociales son el motor garante de su cumplimiento. 


\section{La Carta Mundial por el Derecho a la Ciudad}

Un paso fundamental en la construcción del derecho a la ciudad ha sido la elaboración de la Carta Mundial por el Derecho a la Ciudad ${ }^{10}$ articulada por Habitat International Coalition (HIC).

Un conjunto de movimientos populares, organizaciones no gubernamentales, asociaciones profesionales, foros y redes nacionales e internacionales de la sociedad civil, comprometidas con las luchas sociales por ciudades justas, democráticas, humanas y sustentables, construyeron una Carta Mundial por el Derecho a la Ciudad que busca recoger los compromisos y medidas que deben ser asumidos por la sociedad civil, los gobiernos locales y nacionales, parlamentarios y organismos internacionales para que todas las personas vivan con dignidad en las ciudades.

El proceso que dio pie a esta iniciativa se inició dentro de las actividades preparatorias de la II Conferencia Mundial de Naciones Unidas sobre Medio Ambiente que bajo el título de "Cumbre de la Tierra" se realizó en Río de Janeiro, Brasil, en 1992. El Foro Nacional por la Reforma Urbana (FNRU) de Brasil, la Coalición Internacional para el Hábitat (HIC) y el Frente Continental de Organizaciones Comunales (FCOC) conjuntaron esfuerzos para redactar y suscribir en esa ocasión el Tratado sobre Urbanización "Por ciudades, villas y poblados justos, democráticos y sustentables". Como parte del proceso preparatorio de la Cumbre de la Tierra, varios miembros de HIC organizamos ese mismo año, en Túnez, el Foro Internacional sobre Medio Ambiente, Pobreza y Derecho a la Ciudad, en el que, por primera vez, delegados de nuestra Coalición provenientes de diversas regiones del mundo debatimos sobre el tema. Unos años más tarde, en octubre de 1995, HIC participó en el encuentro "Hacia la Ciudad de la Solidaridad

\footnotetext{
10 Puede verse en

$<$ http://www.hic-net.org/document.php?pid=2423>.
}

y la Ciudadanía", convocado por la UNESCO. Este evento abrió de hecho la participación de esta instancia internacional en el tema de los derechos urbanos. Ese mismo año las organizaciones brasileñas promovían la Carta de Derechos Humanos en la Ciudad, antecedente civil del Estatuto de la Ciudad, que promulgaría años más tarde el gobierno de Brasil.

Otro hito importante en el camino que condujo hacia la iniciativa de formular una Carta Mundial por el Derecho a la Ciudad lo constituyó la Primera Asamblea Mundial de Pobladores, realizada en México en el año 2000, en la que participaron alrededor de 300 delegados de organizaciones y movimientos sociales de 35 países. Bajo el lema "Repensando la ciudad desde la gente", se debatió en torno a la concepción de un ideal colectivo que diera base a propuestas orientadas a la construcción de ciudades democráticas, incluyentes, educadoras, habitables, sustentables, productivas y seguras. Un año después, ya en el marco del primer Foro Social Mundial (2001), se abriría el proceso conducente a la formulación de la Carta. A partir de entonces, y en ocasión de los encuentros anuales del Foro Social Mundial y de otros foros sociales regionales, se ha venido trabajando sobre los contenidos y las estrategias de difusión y promoción de la Carta.

En forma paralela a estas iniciativas de la sociedad civil, algunos gobiernos, tanto a nivel regional, como nacional y local, han venido generando instrumentos jurídicos que buscan normar los derechos humanos en el contexto urbano. Destacan, entre los más avanzados a nivel internacional, la Carta Europea de Salvaguarda de los Derechos Humanos en la Ciudad, firmada hasta ahora por más de 400 ciudades, el Estatuto de la Ciudad de Brasil, decretado en julio de 2001; y, a escala local, la Carta de Montreal y la Carta de la Ciudad de México por el derecho a la ciudad. Cabe destacar también la inclusión reciente del derecho a la 
ciudad en las constituciones de Ecuador y de Bolivia.

\section{Las dimensiones y los componentes del derecho a la ciudad}

El derecho a la ciudad es:

- el derecho a un hábitat que facilite el tejido de las relaciones sociales;

- el derecho a sentirse parte de la ciudad (sentido de cohesión social y construcción colectiva);

- el derecho a vivir dignamente en la ciudad;

- el derecho a la convivencia;

- el derecho al gobierno de la ciudad;

- el derecho a la igualdad de derechos.

Según la Carta Mundial del Derecho a la Ciudad, este nuevo derecho es un derecho colectivo de los habitantes de las urbes, basado en sus usos y costumbres, en especial de los grupos vulnerables y desfavorecidos, para que se les confiera legitimidad de acción y de organización hacia la libre autodeterminación y un nivel de vida adecuado.

Se realiza el derecho a la ciudad cuando hay:

- ejercicio pleno de la ciudadanía y gestión democrática de la ciudad;

- función social de la ciudad y de la propiedad urbana;

- igualdad, no discriminación;

- protección especial de grupos y personas en situación de vulnerabilidad;

- compromiso social del sector privado;

- impulso de la economía solidaria y políticas impositivas progresivas;

- planificación y gestión social de la ciudad;

- producción social del hábitat;

- desarrollo urbano equitativo y sustentable;

- derecho a la información pública;

- libertad e integridad;

- participación política;

- derecho a la justicia;

- derecho a la seguridad pública y a la convivencia pacífica, solidaria y multicultural;

- derecho al agua, al acceso y suministro de servi- cios públicos domiciliarios y urbanos;

- derecho al transporte público y la movilidad urbana;

- derecho a la vivienda;

- derecho al trabajo;

- derecho a un medio ambiente sano y sostenible.

En resumen, la Carta Mundial por el Derecho a la Ciudad basa su propuesta en tres ejes fundamentales:

- El ejercicio pleno de la ciudadanía, es decir el ejercicio de todos los derechos humanos, que aseguran el bienestar colectivo de los habitantes y que promueven la producción y gestión social del hábitat.

- La gestión democrática de la ciudad, a través de la participación de la sociedad de forma directa y activa en el planeamiento y gobierno de las ciudades, fortaleciendo las administraciones públicas a escala local, así como las organizaciones sociales.

- La función social de la propiedad y de la ciudad, donde predomine el bien común sobre el derecho individual de propiedad, lo que implica el uso socialmente justo y ambientalmente sustentable del espacio urbano.

Según Borja, el derecho a la ciudad es una respuesta estratégica, un paradigma frente a la exclusión social y a la segregación espacial generadas por el neoliberalismo. Es una reivindicación para que la gente vuelva a ser dueña de la ciudad y es un escenario de encuentro para la construcción de la vida colectiva.

\section{Las estrategias de conquista del derecho a la ciudad}

Basándose en la constatación de que actualmente se han creado "ciudades sin ciudadanos", el derecho a la ciudad es la bandera de lucha para quienes han perdido el derecho a tener un espacio digno para desarrollarse. El derecho a la ciudad contiene muchos derechos, lo que lo vuelve muy difícil de exigir e implementar. 
Para conquistar el derecho a la ciudad, es necesario primero difundir el concepto y la propuesta de cambio, articular los procesos de movilización social e incidir en la formulación de políticas públicas. Este proceso se ha desarrollado de manera amplia en varios países de América Latina, sobre todo en Brasil, México y Ecuador. El derecho a la ciudad no es una propuesta que solamente haya tenido resonancia en esta región; tiene un carácter claramente global. Existen docenas de situaciones y experiencias, documentadas en distintos países del mundo, que demuestran el derecho a la ciudad, hacia "otra ciudad posible".

El alcance de este desafío implica cambios estructurales profundos en los patrones de producción, consumo y en las formas de apropiación del territorio y de los recursos naturales. El derecho a la ciudad se refiere a la "búsqueda de soluciones contra los efectos negativos de la globalización, la privatización, la escasez de los recursos naturales, el aumento de la pobreza mundial, la fragilidad ambiental y sus consecuencias para la supervivencia de la humanidad y del planeta" (HIC-AL, 2006).

Tomando en cuenta la crisis global que vivimos hoy día, que se concretó a raíz de la crisis del mercado inmobiliario en las ciudades cunas del modelo fordiano, Harvey (2009) afirma que "si esta crisis es fundamentalmente una crisis de urbanización, entonces, la solución ha de ser en el marco de la urbanización, y ahí es donde la lucha por el derecho a la ciudad es fundamental, puesto que tenemos la oportunidad de hacer algo diferente". Sí, existen alternativas al desarrollo urbano basado en la mercantilización, la privatización, el deterioro de los vínculos sociales. El derecho a la ciudad es una herramienta, una propuesta para lograr la construcción de ciudades diferentes en donde todos puedan tener un lugar para vivir en dignidad. Habitat International Coalition (HIC) es parte de esta historia y de esta propuesta. Con sus enfo- ques de derecho a la vivienda adecuada y a la tierra, de producción (gestión) social del hábitat y de justicia social, HIC acompaña procesos y articula el intercambio de experiencias y análisis, que contemplan el derecho a la ciudad como una bandera de lucha y una propuesta política de cambio.

\section{Referencias}

BORJA, Jordi. Los desafíos del territorio y los derechos de la ciudadanía. La factoría, 2000, № 10. $<$ http://www.revistalafactoria.eu/articulo.php?id=1 42>. (Consultado el 15 de agosto de 2010). BORJA, Jordi. La ciudad conquistada. Barcelona: Alianza Editorial. 2003.

HABITAT INTERNATIONAL COALITION et al. Carta Mundial por el Derecho a la Ciudad. 2005. $<$ http://www.hicnet.org/document.php?pid=2663>. (Consultado el 15 de agosto de 2010).

HABITAT INTERNATIONAL COALITION - AMÉRICA LATINA (HIC-AL). El Derecho a la Ciudad y la Carta Mundial por el Derecho a la Ciudad. 2006. <http://www.hic-

al.org/proyectos/derechoalavivienda/desc/derech ociudad2.html>. (Consultado el 15 de agosto de 2010).

HARVEY, David. El Derecho a la Ciudad como alternativa al neoliberalismo. Información resumida de la conferencia de David Harvey en el Foro Social Mundial 2009. 2009.

<http://www.hic-net.org/articles. php?pid=3107> . (Consultado el 15 de agosto de 2010). LEFEBVRE, Henri. Le droit à la ville. Paris: Anthropos, 1968, 3ième édition, 2009 (Trad. cast. El derecho a la ciudad. Barcelona: Península, 1978).

MATHIVET, Charlotte. El derecho a la ciudad: claves para entender la propuesta de crear "otra ciudad posible". In SUGRANYES, Ana y MATHIVET, Charlotte (eds.).Ciudades para tod@s.Por el derecho a la ciudad, propuestas y experien- 
cias. Santiago de Chile: Habitat International Coalition, 2010. <http://www.hicnet.org/content/Ciudades\%20para\%20todosESP.pdf>. (Consultado el 15 de agosto de 2010). NEHLS MARTÍNEZ, N., ORTIZ, E., ZÁRATE, L. (comps.). El derecho a la ciudad en el mundo. Compilación de documentos relevantes para el debate HIC-AL. Ciudad de México: Ediciones HIC-AL, 2008.

PURCELL, Mark. Le Droit à la ville et les mouvements urbains contemporains. Rue Descartes, 2009/1, nº 63 (Droit de cité), p. 40-60.

SIMAY, Philippe. Une autre ville pour une autre vie. Henri Lefebvre et les situationnistes. Rue Descartes, 2009/1, no 63 (Droit de cité), p. 17-26. SUGRANYES, Ana y MATHIVET, Charlotte (eds.). Ciudades para tod@s.Por el derecho a la ciudad, propuestas y experiencias. Santiago de Chile: Habitat International Coalition, 2010. $<$ http://www.hic-
net.org/content/Ciudades\%20para\%20todosESP.pdf>. (Consultado el 15 de agosto de 2010). TORTOSA, José Ma․ Sumak Kawsay, Suma Qamaña, Buen Vivir. Rebelión, 29-08-2009. <http://www.rebelion.org/noticias/2009/8/90660.p df>. (Consultado el 15 de agosto de 2010). VELÁSQUEZ, Fabio (ed.). Conversaciones sobre el derecho a la ciudad. Bogotá: Gente Nueva Editorial, 2007.

ZIBECHI, Raúl. Dispersar el poder. Los movimientos como poderes antiestatales. Santiago de Chile: Editorial Quimantú, 2007.

\section{Cita del artículo:}

SUGRANYES Ana. El derecho a la ciudad. Praxis de la utopía. Hábitat y Sociedad, 2010, № 1, p. 71-79.

$<$ www.us.es.habitatysociedad.es $>$.

http://dx.doi.org/10.12795/HabitatySociedad.2010.i1.05 